\title{
Fossils indicate common ancestor for two primate groups
}

Find suggests Old World monkeys and apes diverged 25 million years ago.

Chris Palmer

15 May 2013

Palaeontologists working in Tanzania have discovered the oldest known fossils from two major primate groups - Old World monkeys, which include baboons and macaques, and apes, which include humans and chimpanzees. The study, published online today in Nature ${ }^{1}$, reveals new information about primate evolution.

A team led by Nancy Stevens, a palaeontologist at Ohio University in Athens, recovered a lone tooth and a jaw fragment with three teeth from a site in the Rukwa Rift Basin in southwestern Tanzania. Precise geological dating of nearby rocks indicates that the fossils are $\mathbf{2 5 . 2}$ million years old, several million years older than any other example from either primate group.

This dating places the discovery in the Oligocene epoch, which extends from about 34 million to 23 million years ago. "Before the discoveries from Rukwa, only three primate genera had been described from all of the late Oligocene, globally," says Stevens. The new find "underscores the importance of palaeontological reconnaissance in under-sampled regions."

More importantly, the fossil trove "fills in a roughly 10-million-year gap in primate evolution," says John Fleagle, an anthropologist at Stony Brook University in New

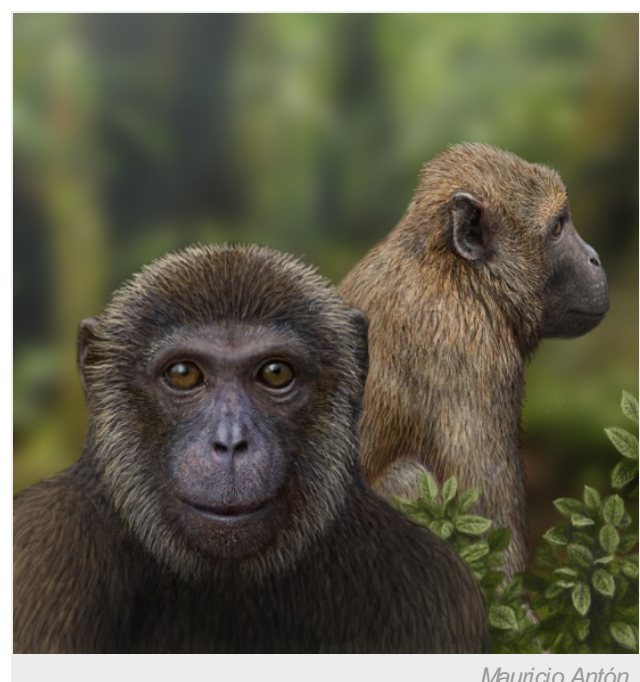

Mauricio Antón

Two new Oligocene primates found in Tanzania, Rukwapithecus fleaglei (foreground left) and Nsungwepithecus gunnelli (background right), are shown here in an artist's reconstruction.

York.

The discovery also reconciles the fossil record analyses of 'molecular clocks' - mutations in DNA that can be traced back to estimate how long ago two species diverged. Molecular clocks suggest that Old World monkeys and apes split from their common ancestor 25 million to 30 million years ago.

"It's a confirmation that the molecular-clock studies are decent estimates for what's going on in geological time," says Michael Steiper, an anthropologist at Hunter College of the City University of New York.

Previous geological evidence gathered by the team suggests that tectonic activity in the East African rift system during the late Oligocene may have helped to trigger the evolutionary divergence between Old World monkeys and apes ${ }^{2}$.

\section{Tale of the tooth}

To place the latest finds in the evolutionary family tree, Stevens' team took high-resolution computed-tomography scans of the fossil teeth to look for subtle variations in the size and shape of several features.

The researchers assigned the single tooth — thought to be a lower third molar — to a species that they call Nsungwepithecus gunnelli. It displays nine characteristics that set it apart from other Old World monkeys. Likewise, the jaw segment with three teeth, from a specimen that the authors have named Rukwapithecus fleaglei, displays nine characteristics that set it apart from other catarrhines the class that includes Old World monkeys and apes.

The species names of the new primates honour Fleagle and palaeontologist Gregg Gunnell of the Duke Lemur Centre in Durham, North Carolina.

Many fossils from the late Oligocene are teeth, so it is common to use them for species identification. However, basing the identification of a new primate on a single tooth fossil has lead to the occasional case of mistaken identity in the fossil record. 
"Given what [the authors] have, they've given the best interpretation possible," says Fleagle.

Nature | doi:10.1038/nature.2013.12997

\section{References}

1. Stevens, N. J. et al. Nature. http://dx.doi.org/10.1038/nature12161 (2013).

2. Robert, E. M. et al. Nature. http://dx.doi.org/10.1038/ngeo1432 (2012). 